\title{
USING MIXED METHOD APPROACH TO UNDERSTAND ACCEPTANCE AND USAGE OF ICT IN NIGERIAN PUBLIC UNIVERSITY
}

\author{
${ }^{1}$ Oye,N. D \\ Department of Information \\ Systems \\ Faculty of Computer Science and \\ Information Systems \\ Universiti Teknologi Malaysia \\ 81310 Skudai, Johor, Malaysia
}

\section{ABSTRACT}

Technology acceptance is about how people accept and adopt some technology to use. The primary target of many technology acceptance studies is to examine how to encourage usage and also analyze what interrupts acceptance and usage of technologies. Using the mixed method approach, the quantitative phase shows that, the perceived usefulness (PE) is significant with $p$-value (.023) and the perceived ease of use (EE) is significant with p-value (.001). These results shows that the intention to accept and use ICT by the academic staff is a function of various concepts including the understanding that ICT is useful and it is not difficult to use. However the qualitative phase shows that it is true that the academicians intent to use ICT but the conditions and environment are not encouraging, classrooms are poorly designed. No regular power supply, no ICT facilities on ground and poor internet connectivity. The mixed method approach has given the true picture of the acceptance and usage of ICT in Nigerian public university. The quantitative phase shows the constructs that have significant influence on acceptance and use of ICT, while the qualitative phase interprets the in-depth meaning of the statistical results and the environmental challenges that most be tackled to realize the full vision.

Keywords: Mixed methods, Quantitative; Qualitative; ICT; Triangulation; Acceptance; Usage

\section{INTRODUCTION}

In the information age where information and communication technology (ICT) is transforming the educational landscape around the world, HEIs in Nigeria should rise up to the challenges ahead (Aduke, 2008; Ekundayo, 2009; Ogunsola \& Aboyade, 2005; Oyelekan, 2004). Public expectation for ICT and educational systems has increase with the ubiquity of digital technologies in daily life. To date, the discourse has been predominantly instrumental, focusing on the skills and the use of ICT in the service of curriculum and instruction.

\author{
${ }^{3}$ Ab.Rahim, N. \\ Department of Information \\ Systems \\ Faculty of Computer Science and \\ Information Systems \\ Universiti Teknologi Malaysia \\ $\underline{81310 \text { Skudai, Johor, Malaysia }}$
}

Although computers have been widely available in educational setting for well over two decades, a concern remains that teachers are neither confident nor competent users of ICT.

The failure to use technology by many academics in the teaching and learning process is of particular concern. The implication for leaders in the delivery of IT service in a university environment is that to meet the reform agenda, not only must they provide administration efficiencies, but also create an environment that appropriately supports technological innovation in the university's teaching and learning. Most of the studies on innovation in higher education have centered on ICT software and hardware designs that are driven from information science (IS) or information technology (IT) perspective of behavioral intention to use the system on an individual Level (Fishbein \& Ajzen, 1975; Venkatesh \& Davis, 2000) . The obvious problem Surry and Ensminger, encountered when discussing about technology is that there are so many different investigations and topics on the subject. Therefore, there is at various levels within any educational system, different expectation and drivers about technology's value and adoption on both personal and organizational level (Surry \& Ensminger, 2006).

(Gubahar, 2008) in his study found that pre-service teachers are willing to use technology but the problem is that no lessons to facilitate them with skills that will transform them into technology competent teachers. In a study by(Archibong \& Effiom, 2009), lack of interest, limited access to ICT facilities and lack of training opportunities were some of the problems associated to ICT usage among the Nigerian University academic staff. (Ijeoma, Joseph, \& Franca, 2010) opined that inadequate ICT facilities, excess workload and funding were identified as major challenges to ICT usage among academic staff in Nigerian universities. The university should start to put in place the structures that will allow the use of ICT. The classrooms are built along the old school of thought, some kids of modification is necessary 
for the classrooms to be suitable for ICT lecture delivery. Globalization is the networking of the world through the global network, to develop global economy. Hence people around the globe are more connected to each other than ever. Undoubtedly, the use of ICT is inevitable and ICT skills are very necessary to participate in the knowledge societies and economies. Certainly, ICT is replacing traditional information and communication gradually.

In Nigeria the attainable infrastructure for ICT in most of the public universities are grossly insufficient. It was noticed that most university students hitherto visit internet off campus because of the conjection on the internet on campus. ICT infrastructure availability is of great significance to anticipate for effective use of ICT in education. According to (Gesci, 2007), "infrastructure refers to hardware or equipment, software applications and services associated with ICTs, including telecommunication, electricity and gird networks."The investigation and examination of the current infrastructure of ICT in education is important to improve the ICT infrastructure. The examination of institution infrastructure entails perusal of existing plan and connectivity of infrastructure for all educational institutions. In summary the challenges to ICT usage among the Nigerian university academicians rages from, lack of funds; lack of time for practice; lack of sponsorship by the university management; no opportunities for training; unable to procure personal ICT facilities; lack of interest in learning; lack of patience to learn; no ICT facilities at the workplace; poor electricity supply; insufficient time due to workload; lack of ICT knowledge and proximity to ICT facilities.

\section{TECHNOLOGY ACCEPTANCE THEORIES AND MODELS}

According to (Louho, Kallioja, \& Oittinen, 2006)P.15), "technology acceptance is about how people accept and adopt some technology to use."The primary target of many technology acceptance studies is to examine how to encourage usage and also analyze what interrupts acceptance and usage of technologies (Kripanont, 2007). This is related to our study with the objective to find the most influential UTAUT construct affecting the behavioral intentions of academicians to accept and use ICT in Nigerian public Universities. Therefore it is important to study the existing technology acceptance models/theories. This will enable the researcher to gather theoretical concept for the study. A number of acceptance and use of technologies have been reported (Barati \& Mohammadi, 2009; Ghobakhloo, Zulkifli, \& Aziz, 2010; Kripanont, 2007; Venkatesh, Davis, Morris, \& Davis, 2003). TRA, MM, TPB, DTPB (Decomposed Theory of Planned Behavior), TAM, TAM2, C- TAM- TPB, MPCU.
These models and theories have been examined and evaluated by several studies (AI- Qeisi, 2009; Barati \& Mohammadi, 2009; Clarke, 1999; Gengatharen \& Standing, 2004; Ghobakhloo et al., 2010; Jayasingh \& Eze, 2010; Kripanont, 2007; Legris, Ingham, \& Collerette, 2003; Minishi-Majanja \& Kiplang'ati, 2005; Perez, Sanchez, Carnicer, \& Jimenez, 2004; Stacy \& Sally, 1999; Szajna, 1996; Van Biljon \& Renaud, 2009; Venkatesh et al., 2003). The scope of a theory/model in predicting and explaining behavior is measured by the amount to which the predictors in the theory could account for a reasonable proportion of the variance in behavioral intention and usage behavior.

\subsection{The Unified Theory of Acceptance and Use of Technology (UTAUT)}

Technology is of little value, unless it is accepted and used. The understanding of technology acceptance and usage is vital and cannot be over emphasized. Unified Theory of Acceptance and Use of Technology (UTAUT), is an important model for studying IT acceptance and usage. The UTAUT model was produced by Venkatesh and his team basing it upon the conceptual and empirical similarities among eight competing technology acceptance models: TRA, TAM, MM, TPB, C-TAMTPB, MPCU, IDT, and SCT (Birth \& Irvine, 2009; Schaper \& P., 2007; Van Biljon \& Renaud, 2009; Venkatesh et al., 2003). [See Figure 1]. The UTAUT model effectively merge key elements from among the initial set of 32 main effects and four moderators from eight different models (Kripanont, 2007; Venkatesh et al., 2003). According to Venkatesh and his team, the theoretical perspective of UTAUT model provides a refined view of how the determinants of intention and behavior evolve over time. Therefore the model postulates three indirect determinant of new technology usage (Performance expectancy, Effort expectancy, and Social influence), and two direct determinants of usage behavior (Intention and Facilitating conditions). The model shows that four moderator, gender, age, voluntariness, and experience were identified to play specific moderating roles to the indirect and direct determinants of technology use behavior.

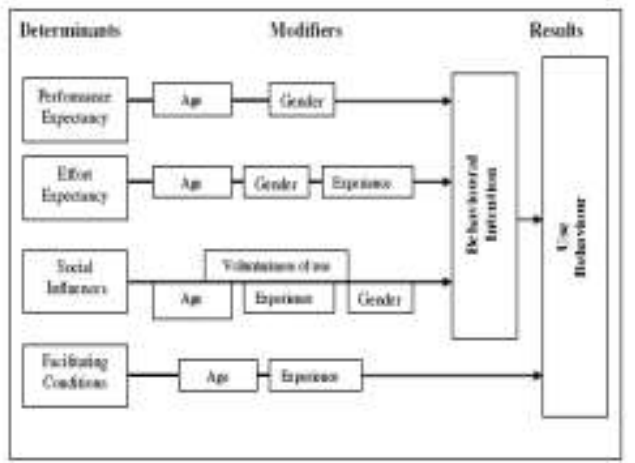


Figure 1: The UTAUT Model (Venkatesh et al, 2003: 447)

\section{OBJECTIVES OF THE RESEARCH:}

This section discusses the results obtained from quantitative phase of the study. For this phase 100 survey questionnaires were administered and collected from Moddibo Adama University of Technology, Yola (MAUTECH). The objective of the study was to: (i) examined the factors associated with ICT acceptance and usage in Nigerian Universities and (ii) measure the most influential factors for the acceptance and usage of ICT by the Nigerian University academicians. The researcher then examines the regression analysis to verify the influence of the four UTAUT constructs (PE, EE, SI, and FC) and Three TAM constructs (Anxiety, Self efficacy, and Attitude towards use of technology) on the behavioral intention of the university academicians to accept and use ICT for teaching and learning. The findings will be used to accept or reject the five null hypotheses stated.

\subsection{Reliability Analysis}

Cronbachs' Alpha was calculated to determine the reliability of the items. Generally reliability numbers greater than 0.6 are considered acceptable in technology acceptance (Zhang, Li \& Sun, 2006).

Tables 1: Reliability Test

\begin{tabular}{|l|l|l|}
\hline University & Cronbachs' Alpha & Number of Items \\
\hline MAUTECH & .719 & 49 \\
\hline
\end{tabular}

From table 1, the constructs have good degree of reliability. Hence the results show that the questionnaire is a reliable measurement instrument and can be used for the research.

\section{RESEARCH APPROACH}

This section comprised of the various research strategies that could be used in conducting mixed method research. We are going to discuss quantitative, qualitative and case study as research strategies. The choice of research approach is influenced by the research paradigm and the objective of the study. This also influences the way the data are collected. There are many types of research strategies, however more attention is focus on qualitative and quantitative (Aina, 2002b; Dixon-Woods, Agarwal, Young, Jones, \& Sutton, 2004; Kothari, 2004). In this study, the mixed method approach adopted is quantitative dominance. Qualitative research involves acquiring indepth responses about what people think, do and feel for enabling researchers to gain insights into attitudes, beliefs, motives and behaviors of the target population. Strictly speaking, qualitative research produces a deeper comprehension of the phenomenon under examination and provides an entire description of the problem under study. On the other hand, according to (Kothari, 2004),p.12), quantitative research is based on the measurement of quantity or amount. It is applicable to phenomenon that can be expressed in terms of quantity. Quantitative techniques add precision in measurements, facilitate economy of description, validate statements, and increase accuracy in prediction and objectivity in social research.

\subsection{The quantitative Phase}

The study begins with a quantitative phase. Quantitative research is used to study populations, or samples that represent populations, and study behavior in a natural setting (Gall, Gall, \& Borg, 2005). Quantitative data in this study was obtained using the survey of the four UTAUT constructs and the TAM variables (Anxiety, Attitudes towards Use and Self efficacy).

\subsection{Quantitative versus Qualitative}

Research methods that are founded on the positivism and interpretivism paradigms are quantitative and qualitative approaches. The quantitative approach is establish on positivism, with an ontological position advocating the existence of only one truth (an object reality), which is independent of human perceptions. From an epistemological perspective, the researcher (observer) and research object examined are independent entities, in the sense that the researcher is able to study the object without being influenced by it or vice versa. Quantitative research makes use of empirical research under the belief that all objects can be compressed to empirical indicators that represent the truth.

On the contrary, the qualitative approach is established on interpretivism, with an ontological position that advocates the existence of multiple realities (Truths) established on a persons' conception of reality. From an epistemological perspective, a humans' mind plays vital role in shaping reality to develop guides on which to compare truth. Contrary to quantitative approach, the researcher and the researched phenomena are interactively linked. Qualitative research gives priority to procedures and meanings and uses of techniques that include in-depth interviews, focus groups and participant observation. The demand for multi-method research on the methodological level is one solution to paradigms' incommensurability. Advocate for this integration state that different methods have different strengths, thus the combination would produce more than what each method could offer alone.

(Morgan, 1998) argues that the mixing can be carried out on the technical aspect which can be done without contravening basic paradigmatic assumptions. Morgam suggested a matrix approach for linking qualitative and quantitative research. Sueber (1973, cited in Johnson et al., 2007) had a different view on how the two approaches can harmonize each other at different stages within the

$$
\text { w w w. i j cton I in e.com }
$$


research procedure. At the research design stage, quantitative data can assist qualitative components, recognizing members of representative sample observations. While qualitative data can assist quantitative components with conceptual as well as instrumental development. At the data collection stage, quantitative data can produce baseline information to check bias, while qualitative data can assist to facilitate assessment of generalisability of quantitative data. Conclusively, at the data analysis stage, qualitative data can play an important role in interpreting, clarifying, describing and validating quantitative results.

In recent years the terms multi-methods, triangulation and mixed method appears in the journals as approaches for facilitating a combination of qualitative and quantitative research (Maxwell \& Loomis, 2003), cited in Tashakkori $\&$ Teddlie, 2003). Mixed method concept was described as an outgrowth of the triangulation of method movement (Dunning, Williams, Abonyi, \& Crooks, 2008). According to (R. Johnson, Onwuegbuzie, \& Turner, 2007), mixed method is a type of research in which a researcher or team of researchers integrate elements of qualitative and quantitative research strategies. As a research type, a mixed method study would involve mixing within a single study, on a programme level; it would involve a mix of methods within a programme of research.

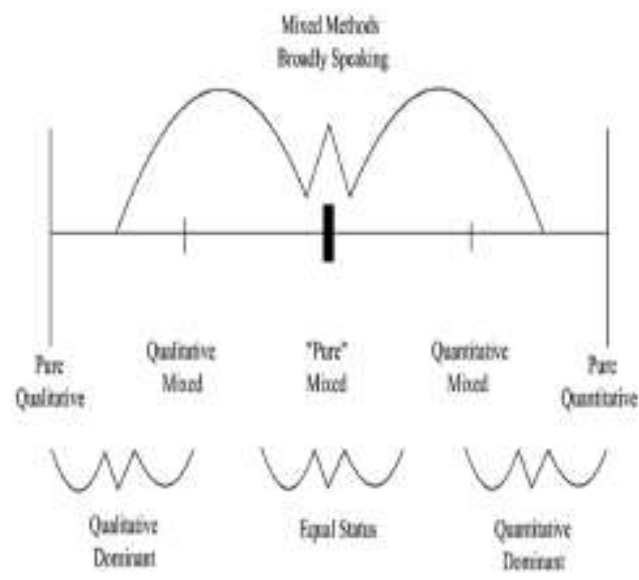

Figure 2: Graphic of the three major research paradigms, including mixed method research

Source: Johnson et al. (2007).

\subsection{Triangulation}

There are a number of ways in which multi-method strategy can occur (Bryman, 2004). Triangulation is one way and involves combining data sources to study the same social phenomena (Tashakkori \& Teddlie, 2003). According to (Bryman, 2004)p.4), triangulation posits variety of meanings, but the integration of two or more research methods within a strategy of convergent reliability is the most commonly referred to. Denzin ( 1978 cited in (R. Johnson et al., 2007), defines four types of triangulations:

i. Data triangulation, this involves gathering data at different times and situations, from different subjects

ii. Investigators triangulation, this involves using more than one field researcher to collect and analyze the data relevant to a specific research object,

iii. Theory triangulation, this involves making explicit references to more than one theoretical tradition, to analyze data, and

iv. Methodological triangulation this involves the combination of different research methods.

Denzin also defined two forms of methodological triangulation: within-methods triangulation, which involves making use of different varieties of the same method, and between-methods triangulation, which involves making use of different methods, such as "qualitative and quantitative "methods in combination.

In social science triangulation is viewed as using multiple viewpoints for checking results. This is also called cross examination (Chen, 2005). Investigators are more confident of results obtain from more than one method. Triangulation is a technique that facilitates validation of data by verifying from more than two sources according to (Altrichter, Feldman, Posch, \& Somekh, 2008).

Table 2: Different types of triangulation (Denzin, 2006)

\begin{tabular}{|l|l|}
\hline $\begin{array}{l}\text { Types of } \\
\text { Triangulation }\end{array}$ & Description \\
\hline Data Triangulation & $\begin{array}{l}\text { Taking more than one way of } \\
\text { measuring data. This involves } \\
\text { time, space, and persons. }\end{array}$ \\
\hline $\begin{array}{l}\text { Investigator } \\
\text { Triangulation }\end{array}$ & $\begin{array}{l}\text { This will involve using multiple } \\
\text { researchers or observers in an } \\
\text { investigation. }\end{array}$ \\
\hline Theory Triangulation & $\begin{array}{l}\text { This involves using more than } \\
\text { one theoretical scheme in the } \\
\text { interpretation of the phenomena. }\end{array}$ \\
\hline $\begin{array}{l}\text { Methodological } \\
\text { Triangulation }\end{array}$ & $\begin{array}{l}\text { This involves using more than } \\
\text { one method to gather the data } \\
\text { thus mixing Quantitative with } \\
\text { Qualitative research methods in } \\
\text { order to get a more } \\
\text { comprehensive result from the } \\
\text { study. }\end{array}$ \\
\hline
\end{tabular}

w w w. ijctonline.com 
This research is using between-methods triangulation. Therefore it will embark on mixing quantitative and qualitative research methods in order to get comprehensive result. In addition the study involves using more than one theoretical scheme; consequently the research will use both data and methodological triangulation.

\section{MULTIPLE ANALYSIS}

REGRESSION

Multiple regression analysis will be conducted after the reliability test. Generally reliability numbers greater than 0.6 are considered acceptable in technology acceptance literature (Zhang, Li, \& Sun, 2006). As summarized in the table 1, reliability analysis was conducted, for the 49 items using Cronbach's Alpha. The reliability analysis of MAUTECH was conducted using SPSS 17.

In statistics, regression analysis includes many techniques for modeling and analyzing several variables, when the focus is on the relationship between a dependent variable and one or more independent variables. In this study, we use multiple regression analysis to explore the predictive ability of the influence of UTAUT and TAM independent variables (PE, EE, SI, FC, SE, ATUT, and AX) on the dependent variable Behavioral Intention (BI).

5.1 Model Summary provides the value of $R$ which is the correlation coefficient. $R^{2}$ is the variance and this indicates the strength of the relationship, this represents the proportion of variance in the dependent variable that is explained by the independent variable. The larger the $\mathrm{R}^{2}$ value, the higher the influence. (See appendix).

5.1.1 ANOVA summaries the result of an analysis and shows the significance of $\mathrm{F}$ ratio, which for this study will be a $95 \%$ confidence level. Therefore a score less than $\mathrm{P}=0.05$ will be significant $(\mathrm{p}<0.05)$. (See appendix).

5.1.2 Coefficient analysis identifies through the $t-$ statistics, if we can reject the null hypothesis. It informs us if a relationship between the independent variable and the dependent variable exist (Garson, 2006).

\subsection{The Qualitative Phase}

Qualitative data was obtained through interview conducted with some of the participants (Lecturers). We are going to use a standardized open-ended interview approach: Interview questions are written out in advance exactly the way they are to be asked during the interview. Interview Questions are as follows:

i. Within your academic program so far how thorough is the acceptance and use of ICT? What would you recommend to the university?

ii. Do you intend to use ICT in your teaching? iii. What are your thoughts on the university curriculum for education on the issue of acceptance and use of ICT?

iv. What would be the most important thing that would help you to accept and use ICT in your academic work?

v. Do you support the idea of developing guidelines for ICT acceptance and usage for university academic staff?

\section{CASE STUDY: Moddibo Adama University of Technology (MAUTECH)}

100 questionnaires were administered and collected. Using regression analysis, the study want to verify the influence of the four constructs of UTAUT (PE, EE, SI, and FC) and three TAM constructs: anxiety, self efficacy, and attitudes towards use of technology on the behavioral intention of the university academicians, towards the acceptance and use of ICT for teaching and learning. These findings will be used to accept or reject the five null hypotheses stated:

$\mathrm{HO}_{1}$ : The academic staff of MAUTECH rejects acceptance and usage of ICT in their workplace.

$\mathrm{HO}_{2}$ : UTAUT do not predict the successful acceptance and use of ICT by MAUTECH academic staff.

$\mathrm{HO}_{3}$ : Computer self efficacy does have impact on MAUTECH academic staff to accept and use ICT.

$\mathrm{HO}_{4}$ : MAUTECH academicians' attitudes towards ICT influence their acceptance and use of the technology.

$\mathrm{H}_{5}$ : Anxiety about computer use does have an impact on MAUTECH academic staff acceptance and use of ICT.

\subsection{Influence of PE on BI from (table 3)}

\section{Discussion (1)}

From model 1, PE1-10 variables contributed (.200) of the total variation observed on the behavioral intention of the academic staff to accept and use ICT. The correlation and $\mathrm{R}^{2}$ are (.448 and .200) respectively. The regression equation $\mathrm{Y}=2.757-0.049 \mathrm{PE}_{1}+0.005 \mathrm{PE}_{2}+0.133 \mathrm{PE}_{3}+$ $0.041 \mathrm{PE}_{4}+0.148 \mathrm{PE}_{5}-0.152 \mathrm{PE}_{6}+0.121 \mathrm{PE}_{7}-0.035 \mathrm{PE}_{8}-$ $0.069 \mathrm{PE}_{9}+0.092 \mathrm{PE}_{10}$ is significant with $\mathrm{P}$-value (.023). The coefficient shows that none of the independent variables PE 1-10 are significant. Therefore they have no positive influence on the behavioral intention to accept and use ICT.

From model 2, PE 1-10 contributed (.101) of the total variation observed on behavioral intention of the academic staff to accept and use ICT. The correlation and $\mathrm{R}^{2}$ are (.318 and .101) respectively. The regression equation is not significant with p-value (.448). The 
ISSN: 2277-3061 (online)

Table 3: Regression Analysis Summary Outcome: MAUTECH

\begin{tabular}{|c|c|c|c|c|c|}
\hline Table & Independent & Dependent & $\mathrm{R}$ & $\mathrm{R}^{2}$ & Significant \\
\hline 1 & PE 1-10 & $\mathrm{BI}(1)$ & .448 & .200 & .023 \\
\hline 2 & PE $1-10$ & $\mathrm{BI}(2)$ & .318 & .101 & .448 \\
\hline 3 & PE 1-10 & $\mathrm{BI}(3)$ & .318 & .101 & .460 \\
\hline 4 & PE 1-10 & $\mathrm{BI}(4)$ & .316 & .100 & .462 \\
\hline 5 & PE 1-10 & $\mathrm{BI}(5)$ & .418 & .175 & .058 \\
\hline 6 & EE 1-8 & $\mathrm{BI}(1)$ & .358 & .128 & .117 \\
\hline 7 & EE 1-8 & $\mathrm{BI}(2)$ & .323 & .104 & .242 \\
\hline 8 & EE 1-8 & $\mathrm{BI}(3)$ & .429 & .184 & .016 \\
\hline 9 & EE 1-8 & BI(4) & .497 & .247 & .001 \\
\hline 10 & EE 1-8 & $\mathrm{BI}(5)$ & .493 & .243 & .001 \\
\hline 11 & ATUT 1-6 & $\mathrm{BI}(1)$ & .375 & .141 & .025 \\
\hline 12 & ATUT 1-6 & $\mathrm{BI}(2)$ & .328 & .107 & .095 \\
\hline 13 & ATUT 1-6 & $\mathrm{BI}(3)$ & .310 & .096 & .147 \\
\hline 14 & ATUT 1-6 & $\mathrm{BI}(4)$ & .423 & .179 & .005 \\
\hline 15 & ATUT 1-6 & $\mathrm{BI}(5)$ & .389 & .151 & .016 \\
\hline 16 & SI 1-6 & $\mathrm{BI}(1)$ & .372 & .138 & .028 \\
\hline 17 & SI 1-6 & $\mathrm{BI}(2)$ & .279 & .078 & .263 \\
\hline 18 & SI 1-6 & $\mathrm{BI}(3)$ & .364 & .132 & .038 \\
\hline 19 & SI $1-6$ & $\mathrm{BI}(4)$ & .476 & .227 & .000 \\
\hline 20 & SI 1-6 & $\mathrm{BI}(5)$ & .489 & .240 & .000 \\
\hline 21 & $\mathrm{FC} 1-5$ & $\mathrm{BI}(1)$ & .378 & .143 & .012 \\
\hline 22 & FC 1-5 & $\mathrm{BI}(2)$ & .289 & .083 & .140 \\
\hline 23 & FC $1-5$ & $\mathrm{BI}(3)$ & .278 & .077 & .181 \\
\hline 24 & FC $1-5$ & $\mathrm{BI}(4)$ & .304 & .093 & .098 \\
\hline 25 & FC $1-5$ & $\mathrm{BI}(5)$ & .410 & .168 & .004 \\
\hline 26 & SE 1-5 & $\mathrm{BI}(1)$ & .360 & .130 & .022 \\
\hline 27 & SE 1-5 & $\mathrm{BI}(2)$ & .249 & .062 & .302 \\
\hline 28 & SE 1-5 & $\mathrm{BI}(3)$ & .266 & .071 & .231 \\
\hline 29 & SE 1-5 & $\mathrm{BI}(4)$ & .415 & .172 & .003 \\
\hline 30 & SE 1-5 & BI(5) & .445 & 198 & .001 \\
\hline 31 & AX 1-4 & $\mathrm{BI}(1)$ & .359 & .129 & .010 \\
\hline 32 & AX 1-4 & $\mathrm{BI}(2)$ & .210 & .044 & .366 \\
\hline 33 & AX 1-4 & $\mathrm{BI}(3)$ & .299 & .090 & .063 \\
\hline
\end{tabular}




\section{p $<0.05 "$}

coefficient shows that none of the variables PE1-10 are significant. Therefore we conclude that, they have no positive influence on behavioral intention to accept and use ICT.

From model 3, PE 1-10 contributed (.101) of the total variation observed on the behavioral intention of the academic staff to accept and use ICT. The correlation and $\mathrm{R}^{2}$ are (.318 and .101) respectively. The regression equation is not significant with p-value (.460). The coefficient shows that none of the independent variables are significant. Therefore we conclude that PE 1-10 has no positive influence on the behavioral intention to accept and use ICT.

From model 4, PE 1-10 contributed (.100) of the total variation observed on behavioral intention of the academic staff to accept and use ICT. The correlation and $\mathrm{R}^{2}$ are (.316 and .100) respectively. The regression equation is not significant with p-vale (.462). The coefficient shows that all the variables are not significant. We conclude that the independent variables have no positive influence on the behavioral intention to accept and use ICT.

From model 5, PE 1-10 contributed (.175) of the total variation observed on the behavioral intention of the academic staff to accept and use ICT. The correlation and $\mathrm{R}^{2}$ are (.418 and .175) respectively. The regression equation is not significant with p-value (.058). However the coefficient shows that PE8 is significant with p-value (.046). We therefore conclude that PE8 has positive influence on the behavioral intention to accept and use ICT.

\subsection{Influence of EE on BI}

\section{Discussion (2)}

From model 6, EE 1-8 contributed (.128) of the total variation observed on the behavioral intention of the academic staff to accept and use ICT. The correlation and $\mathrm{R}^{2}$ are (.358 and .128) respectively. The regression equation $\mathrm{Y}=3.290-0.049 \mathrm{EE}_{1}+0.011 \mathrm{EE}_{2}-0.049 \mathrm{EE}_{3}+$ $0.272 \mathrm{EE}_{4}+0.047 \mathrm{EE}_{5}-0.011 \mathrm{EE}_{6}-0.072 \mathrm{EE}_{7}+0.068 \mathrm{EE}_{8}$, is not significant with $\mathrm{p}$-value (.117). The coefficient shows that only EE4 is significant with p-value (.010), and it has positive influence on the behavioral intention to accept and use ICT.

From model 7, EE 1-8 contributed (.104) of the total variation observed on behavioral intention of the academic staff to accept and use ICT. The correlation is (.323) and $\mathrm{R}^{2}$ is (.104). The regression equation is not significant with p-value (.242) and also the coefficient shows that EE 1-8, are not significant. Therefore we conclude that they have no positive influence on the behavioral intention to accept and use ICT.

From model 8, EE1-8 contributed (.184) of the total variation observed on the behavioral intention of the academic staff to accept and use ICT. The correlation and $\mathrm{R}^{2}$ are (.429 and .184) respectively. The regression equation is significant with p-value (.016). The coefficient shows that EE1 is highly significant with p-value (.000). We conclude that EE1 has positive influence on the behavioral intention to accept and use ICT.

From model 9, EE 1-8 contributed (.247) of the total variation observed on the behavioral intention of the academicians to accept and use ICT. The correlation and $\mathrm{R}^{2}$ are (.497 and .247) respectively. The regression equation is significant with p-value (.001) and the coefficient shows that EE3 and EE5 are both significant with p-values (.033 and .002) respectively. Therefore they have positive influence on the behavioral intention to accept and use ICT.

From model 10, EE 1-8 contributed (.243) of the total variation observed on the behavioral intention of the academic staff to accept and use ICT. The correlation and the $\mathrm{R}^{2}$ are (.493 and .243) respectively. The regression equation is significant with p-value (.001). The coefficient shows that EE4 and EE5 are both significant with p-values (.043 and .054). Therefore they have positive influence on the behavioral intention to accept and use ICT.

\subsection{Influence of ATUT on BI}

\section{Discussion (3)}

From model 11, ATUT 1-6 contributed (.141) of the total variation observed on behavioral intention of the academicians to accept and use ICT. The correlation and the $\mathrm{R}^{2}$ are $(.375$ and .141) respectively. The regression equation $\mathrm{Y}=1.015+0.166 \mathrm{ATUT}_{1}+0.180 \mathrm{ATUT}_{2}+$ $0.036 \mathrm{ATUT}_{3}+0.173 \mathrm{ATUT}_{4}+0.007 \mathrm{ATUT}_{5}+$ $0.272 \mathrm{ATUT}_{6}$, is significant with $\mathrm{p}$-value (.025). The coefficient shows that only ATUT6 is significant with pvalue (.011). Therefore it has positive influence on the behavioral intention to accept and use ICT.

From model 12, ATUT 1-6 contributed (.107) of the total variation observed on behavioral intention of the academicians to accept and use ICT. The correlation and the $\mathrm{R}^{2}$ are (.328 and .107) respectively. The regression equation is not significant with p-value (.095). However 
the coefficient shows that ATUT2 is significant with pvalue (.003). We conclude that it has positive influence on the behavioral intention to accept and use ICT.

From model 13, ATUT 1-6 contributed (.096) of the total variation observed on behavioral intention of the academicians to accept and use ICT. The correlation is (.310) and $\mathrm{R}^{2}$ is (.096). The regression equation is not significant with p-value (.147) and the coefficient shows that all variables ATUT 1-6 are not significant. Therefore they have no positive influence on the behavioral intention to accept and use ICT.

From model 14, ATUT 1-6 contributed (.179) of the total variation observed on behavioral intention of the academicians to accept and use ICT. The correlation and the $\mathrm{R}^{2}$ are (.423 and .179) respectively. The regression equation is significant with p-value (.005) and the coefficient shows that ATUT1 is also significant with pvalue (.006). Therefore it has positive influence on the behavioral intention to accept and use ICT.

From model 15, ATUT 1-6 contributed (.151) of the total variation observed on the behavioral intention of the academicians to accept and use ICT. The correlation and the $\mathrm{R}^{2}$ are (.389 and .151) respectively. The regression equation is significant with p-value (.016) but the coefficient shows that none of the independent variables are significant. Therefore we conclude that ATUT 11-6, have no positive influence on the behavioral intention to accept and use ICT.

\subsection{Influence of SI on BI}

\section{Discussion (4)}

From model 16, SI 1-6 contributed (.138) of the total variation observed on the behavioral intention of the academicians to accept and use ICT. The correlation and the $\mathrm{R}^{2}$ are (.372 and .138) respectively. The regression equation $\mathrm{Y}=3.079+0.277 \mathrm{SI}_{1}+0.166 \mathrm{SI}_{2}-0.063 \mathrm{SI}_{3}-$ $0.081 \mathrm{SI}_{4}+0.011 \mathrm{SI}_{5}-0.037 \mathrm{SI}_{6}$, is significant with p-value (.028) and the coefficient shows that SI1 is also significant with p-value (.024). Therefore it has positive influence on the behavioral intention to accept and use ICT.

From model 17, SI 1-6 contributed only (.078) of the total variation observed on behavioral intention of the academicians to accept and use ICT. The correlation is (.279) and the $\mathrm{R}^{2}$ is (.078). The regression equation is not significant with p-value (.263); however the coefficient shows that SI6 is significant with p-value (.033). Therefore it has positive influence on the behavioral intention to accept and use ICT.

From model 18, SI 1-6 contributed (.132) of the total variation observed on behavioral intention of the academicians to accept and use ICT. The correlation and the $\mathrm{R}^{2}$ are (.364 and .132) respectively. The regression

$\mathbf{5 4}$ | P a g e equation is significant with p-value (.038), and the coefficient shows that SI6 is also significant with p-value (.002). Therefore it has positive influence on the behavioral intention to accept and use ICT.

From model 19, SI 1-6 contributed (.227) of the total variation observed on behavioral intention of the academicians to accept and use ICT. The correlation and the $\mathrm{R}^{2}$ are (.476 and .227) respectively. The regression equation is significant with p-value (.000), and the coefficient shows that both SI2 and SI5 are significant with p-values (.008 and .001) respectively. Therefore they have positive influence on the behavioral intention to accept and use ICT.

From model 20, SI 1-6 contributed (.240) of the total variation observed on the behavioral intention of the academicians to accept and use ICT. The correlation and the $\mathrm{R}^{2}$ are (.489 and .240) respectively. The regression equation is significant with p-value (.000) and the coefficient shows that SI1 is also significant with p-value (.001). Therefore it has positive influence on the behavioral intention to accept and use ICT.

\subsection{Influence of FC on BI}

\section{Discussion (5)}

From model 21, FC 1-5 contributed (.143) of the total variation observed on the behavioral intention of the academicians to accept and use ICT. The correlation and the $\mathrm{R}^{2}$ are (.378 and .143) respectively. The regression equation $\mathrm{Y}=4.447-0.037 \mathrm{FC}_{1}+0.081 \mathrm{FC}_{2}-0.240 \mathrm{FC}_{3}-$ $0.031 \mathrm{FC}_{4}+0.064 \mathrm{FC}_{5}$, is significant with p-value (.012). The coefficient shows that FC3 is also significant with pvalue (.003). Therefore it has positive influence on the behavioral intention to accept and use ICT.

From model 22, FC 1-5 contributed (.083) of the total variation observed on the behavioral intention of the academicians to accept and use ICT. The correlation is (.289) and the $\mathrm{R}^{2}$ is (.083). The regression equation is not significant with p-value (.140), but the coefficient shows that FC4 is significant with p-value (.012). Hence it has positive influence on the behavioral intention to accept and use ICT.

From model 23, FC 1-5 contributed (.077) of the total variation observed on behavioral intention of the academicians to accept and use ICT. $\mathrm{R}^{2}$ is (.077) and the correlation is (.278). The regression equation is not significant with p-value (.181). The coefficient shows that all the independent variables are not significant. Therefore FC 1-5 has no positive influence on behavioral intention to accept and use ICT.

From model 24, FC 1-5 contributed (.093) of the total variation observed on behavioral intention of the academicians to accept and use ICT. The correlation and $\mathrm{R}^{2}$ are (.304 and .093) respectively. The regression 
equation is not significant with p-value (.098), but the coefficient shows that FC5 is significant with p-value (.035). Therefore it has positive influence on the behavioral intention to accept and use ICT.

From model 25, FC $1-5$ contributed (.168) of the total variation observed on behavioral intention of the academicians to accept and use ICT. The correlation and the $\mathrm{R}^{2}$ are (.410 and .168) respectively. The regression equation is significant with p-value (.004) and the coefficient shows that FC2 and FC5 are both significant with p-values (.025 and .034) respectively. Therefore they have positive influence on the behavioral intention to accept and use ICT.

\subsection{Influence of SE on BI}

\section{Discussion (6)}

From model 26, SE $1-5$ contributed (.130) of the total variation observed on the behavioral intention of the academicians to accept and use ICT. The correlation and the $\mathrm{R}^{2}$ are (.360 and .130) respectively. The regression equation $\mathrm{Y}=1.783+0.112 \mathrm{SE}_{1}-0.060 \mathrm{SE}_{2}+0.102 \mathrm{SE}_{3}+$ $0.188 \mathrm{SE}_{4}+0.242 \mathrm{SE}_{5}$ is significant with $\mathrm{p}$-value (.022), and the coefficient shows that SE5 is also significant with p-value (.041). Therefore it has positive influence on the behavioral intention to accept and use ICT.

From model 27, SE 1-5 contributed (.062) of the total variation observed on the behavioral intention of the academicians to accept and use ICT. The correlation is (.249) and the $\mathrm{R}^{2}$ is (.062). The regression equation is not significant with p-value (.302). The coefficient shows that all the independent variables SE 1-5 are also not significant. Therefore they have no positive influence on the behavioral intention to accept and use ICT.

From model 28, SE 1-5 contributed (.071) of the total variation observed on the behavioral intention of the academicians to accept and use ICT. The correlation and the $\mathrm{R}^{2}$ are (.266 and .071) respectively. The regression equation is not significant with p-value (.231). The coefficient shows that only SE5 is significant with p-value (.043). Therefore it has positive influence on the behavioral intention to accept and use ICT.

From model 29, SE 1-5 contributed (.172) of the total variation observed on the behavioral intention of the academicians to accept and use ICT. The correlation and $\mathrm{R}^{2}$ are (.415 and .172) respectively. The regression equation is significant with p-value (.003), and the coefficient shows that SE4 is also significant with p-value (.041). Therefore it has positive influence on the behavioral intention to accept and use ICT.

From model 30, SE 1-5 contributed (.198) of the total variation observed on the behavioral intention of the academicians to accept and use ICT. The correlation and the $\mathrm{R}^{2}$ are (.445 and .198) respectively. The regression

55 | $\mathrm{P}$ a g e equation is significant with p-value (.001) and the coefficient shows that SE4 is significant with p-value (.000). Therefore it has positive influence on the behavioral intention to accept and use ICT.

\subsection{Influence of $\mathrm{AX}$ on BI}

\section{Discussion (7)}

From model 31, AX 1-4 contributed (.129) of the total variation observed on behavioral intention of the academicians to accept and use ICT. The correlation and the $\mathrm{R}^{2}$ are (.359 and .129) respectively. The regression equation $\mathrm{Y}=4.923-0.160 \mathrm{AX}_{1}-0.054 \mathrm{AX}_{2}-0.132 \mathrm{AX}_{3}+$ $0.005 \mathrm{AX}_{4}$, is significant with p-value (.010), and the coefficient shows that $\mathrm{AX} 1$ is also significant with $\mathrm{p}$ value (.025). We conclude that it has positive influence on the behavioral intention to accept and use ICT.

From model 32, AX 1-4 contributed (.044) of the total variation observed on behavioral intention of the academicians to accept and use ICT. The correlation is (.210) and the $\mathrm{R}^{2}$ is (.044). The regression equation is not significant with $\mathrm{p}$-value (.366). In addition the coefficient shows that none of the independent variables AX 1-4 are significant. Therefore we conclude that they have no positive influence on behavioral intention to accept and use ICT.

From model 33, AX 1-4 contributed (.090) of the total variation observed on behavioral intention of the academicians to accept and use ICT. The correlation is (.299) and $\mathrm{R}^{2}$ is (.090). The regression equation is not significant with p-value (.063). The coefficient shows that only AX3 is significant with p-value (.004). Therefore it has positive influence on the behavioral intention to accept and use ICT.

From model 34, AX 1-4 contributed (.120) of the total variation observed on behavioral intention of the academicians to accept and use ICT. The correlation and the $\mathrm{R}^{2}$ are (.347 and .120) respectively. The regression equation is significant with p-value (.015), and the coefficient shows that $\mathrm{AX} 1$ is also significant with $\mathrm{p}$ value (.002). Therefore it has positive influence on the behavioral intention to accept and use ICT.

From model 35, AX 1-4 contributed (.133) of the total variation observed on behavioral intention of the academicians to accept and use ICT. The correlation and the $\mathrm{R}^{2}$ are (.364 and .133) respectively. The regression equation is significant with p-value (.008), and the coefficient shows that AX3 is significant with p-value (.025). Therefore it has positive influence on the behavioral intention to accept and use ICT.

\subsection{Discussion on the Hypotheses}

H0 $\mathbf{0}_{1}$ : The academic staff of MAUTECH rejects acceptance and usage of ICT in their workplace

w w w. i j ctonline.com 
Performance expectancy is the extent an individual believes the system will help them do their jobs better (PU). Model 1, shows that the independent variable (PE110) have positive influence on the behavioral intention of the academicians to accept and use ICT. This is significant with p-value (.023). Effort expectancy is related to how ease an individual believes the system is to use (PEOU). Models 9, shows that effort expectancy have positive influence on the behavioral intention of the academicians to accept and use ICT, and this is significant with p-values (.001). We therefore conclude that the academic staff of MAUTECH believes that ICT is useful and easy to use. This influences their behavioral intention to accept and use ICT in their workplace. Therefore we reject the null hypothesis $\left(\mathrm{HO}_{1}\right)$ and accept the alternative $\left(\mathrm{H}_{1}\right)$ which states that MAUTECH academic staff does not reject ICT acceptance and usage in their workplace.

H0$_{2}$ : UTAUT do not predict the successful acceptance and use of ICT by the MAUTECH academic staff.

The UTAUT aims to explain user intention to use IS and subsequently usage behavior. The theory holds that four key constructs (PE, EE, SI \& FC) are direct determinants of usage intention and behavior ( Venkatesh et al. ,2003). From model 1, performance expectancy is significant with p-value (.023); from model 9, effort expectancy is significant with p-value (.001); from model 20, social influence is significant with p-value (.000) and model 25 shows that, facilitating condition is significant with $\mathrm{p}$ value (.004). This shows that each of the four constructs of UTAUT have positive influence on the behavioral intention of the MAUTECH academicians to accept and use ICT. Since the four constructs have significant relationship with the behavioral intention to accept and use ICT, we therefore reject the null hypothesis $\left(\mathrm{HO}_{2}\right)$ and accept the alternative $\left(\mathrm{H}_{2}\right)$, which states that, UTAUT do predict successful acceptance and use of ICT by the academicians in MAUTECH.

H03 $_{3}$ : Computer self efficacy does have impact on MAUTECH academic staff to accept and use ICT.

Self efficacy is related to an individuals' confidence in his/her ability to perform the behavior required to produce specific outcome. Model 35, shows that computer self efficacy have positive influence on the behavioral intention to accept and use ICT, which states that 'I would use ICT in my class frequently'. This is significant with pvalue (.001). Therefore we accept the null hypothesis $\left(\mathrm{HO}_{3}\right)$.

H0: MAUTECH academicians' attitudes towards ICT influence their acceptance and use of the technology.

Model 14, shows that the independent variables ATUT have positive influence on the behavioral intention of MAUTECH academicians to accept and use the technology. This is significant with p-value (.005). This

56 | $\mathrm{P}$ a g e shows that attitudes towards the use of ICT by the academic staff have positive influence on their behavioral intention to accept and use the technology. Therefore we accept the null hypothesis $\left(\mathrm{HO}_{4}\right)$.

H05: Anxiety about computer use does have an impact on MAUTECH academic staff acceptance and use of ICT.

Anxiety is related to fear of computer (ICT) when using one. Model 35, shows that the independent variables AX have positive influence on the behavioral intention of MAUTECH academicians to accept and use ICT. This is significant with p-value (.008). Therefore we accept the null hypothesis $\left(\mathrm{HO}_{5}\right)$. This shows that some MAUTECH academicians are still having fear of using ICT for teaching and learning.

\subsection{Summary}

We have verified the influence of the four UTAUT constructs and the three TAM constructs on the behavioral intention of the university academicians towards the acceptance and use of ICT for teaching and learning. The UTAUT model theory was verified using regression analysis to understand the behavioral intention of the university academic staff towards acceptance and use of ICT in their workplace.

The UTAUT constructs significantly correlated with behavioral intention to accept and use ICT. These are the factors associated with ICT acceptance and usage in MAUTECH. According to our results Perceived Usefulness (PU) has $\mathbf{R}^{\mathbf{2}}=\mathbf{. 2 0 0}$ and significant with $\mathrm{p}$ value (.023), (model 1), and Perceived ease of use (PEOU), has $\mathbf{R}^{\mathbf{2}}=\mathbf{. 2 4 7}$, significant with $\mathrm{p}$-vale (.001), (model 9). This has answered objective 1, which is to examine the factors associated with ICT acceptance and usage in MAUTECH.

The study confirms that the most influential UTAUT constructs influencing the behavioral intention of the academic staff to accept and use ICT is Effort expectancy (EE) in MAUTECH (model 9), with $\mathbf{R}=\mathbf{. 4 9 7}$ and $\mathbf{R}^{\mathbf{2}}=$ .247, and significant with p-value (.001), (Answered Objective 2).

Again it shows that the most influential constructs outside UTAUT model influencing the behavioral intention of the academicians to accept and use ICT is self efficacy $(\mathrm{SE})$ in MAUTECH (model 30), with $\mathbf{R}=\mathbf{. 4 4 5}$ and $\mathbf{R}^{\mathbf{2}}=\mathbf{. 1 9 8}$, and significant with p-value (.001), (Answered Objective 2).

UTAUT model predict successful acceptance and use of ICT in MAUTECH. The study also certifies that some of the academicians in MAUTECH are still having the fear of using ICT for their teaching and learning. Therefore anxiety about ICT does have an impact on the academicians of MAUTECH.

$$
\text { w w w. ijctonline.com }
$$




\section{MIXED METHOD RESULT}

Mixed methods allow the richness of qualitative themes to be used along with quantitative data. Integrating mixed method approach enables the integration of the qualitative data at the level of statistical analysis. Triangulation is a powerful technique that facilitates quantitative (validation) and qualitative (inquiry) studies. Conducting mixed methods research involves collecting, analyzing and interpreting quantitative and qualitative data in a single study ( Tashakkori and Teddlie, 2003). There is no discrete list for mixed method design options, therefore researchers should plan to develop a design that give solution to their own research questions within the constraint and boundaries of the study context (Johnson \& Onwuegbuzie, 2004)p:2).

Qualitative and quantitative approach can be integrated in three different forms, which are called parallel, sequential, and iterative. In parallel approaches, the quantitative and qualitative research teams work separately but compare and combine findings during analysis phase. This approach is best suited for very large projects, such as national level poverty assessments.

Sequential and iterative approaches, which are referred to as participatory econometrics, considers varying degrees of dialogue between qualitative and quantitative phases of the research cycle and are best suited to projects of modest scale and scope. According to (Rao, 1998; Rao \& Ibanez, 2003), sequential approach entails three steps:

i. Focus-group discussion, in-depth interviews techniques to obtain a grounded understanding of the issues.

ii. Constructing a survey instruments that integrates understanding from the field.

iii. Deriving hypotheses and testing with survey data.

In this study we are going to use sequential approach, where the survey results shows the relationship between behavioral intention of university academic staff towards acceptance and use of ICT. While the in-depth interview data help to suggest or indicate a relation between the academic staff and the university environment. The sequential mixed method approach for this study is quantitative dominance (QUAN---QUAL). It answers one type of question by collecting and analyzing two types of data (Quantitative and Qualitative).

\subsection{Sequential Design}

Sequential designs facilitate combining qualitative and quantitative work, but do so in a segmented way. Sequential mixed methods data collection strategies involves collecting data in an iterative process whereby

57 | P a g e the data collected in one phase contribute to the data collected in the next Phase (Creswell \& Plano Clark, 2007)p:121). Sequential designs in which quantitative data are collected first can use statistical methods to determine which findings to augment in the qualitative phase.

\section{INTEGRATING QUANTITATIVE AND QUALITATIVE RESULTS OF MAUTECH}

Summary of Hypotheses Discussions:

- The academic staffs of MAUTECH do not reject ICT acceptance and usage in their workplace.

- UTAUT do predict successful acceptance and use of ICT by the academicians in MAUTECH.

- Computer self efficacy does have impact on MAUTECH academic staff to accept and use ICT.

- MAUTECH academicians' attitudes towards ICT influence their acceptance and use of the technology.

- Anxiety about computer use does have an impact on MAUTECH academic staffs' acceptance and use of ICT.

The UTAUT constructs significantly correlated with behavioral intention to accept and use ICT as revealed by the discussion on the hypotheses. According to our quantitative results, performance expectancy, which is related to the extent an individual believes that using the system will help him or her attain gains in job performance (Venkatesh et ,al., 2003), which is also referred to as perceived usefulness has correlation, $\mathrm{R}=.448$ and variance, $\mathrm{R}^{2}=.200$, significant with p-value (.023).

8.1 When asked whether they intend to use ICT in their teaching.

Interviewee (1): I am a lover of ICT and I intend to use it. The use of ICT makes life easy for the academicians. The use of ICT will assist the academic staff to cover more area of the course he is teaching. There is the willingness to use ICT, but the facilities, the condition and environment are not encouraging and classrooms are poorly designed.

Interviewee (2): The university academic staff as a matter of policy has the intention to use ICT for teaching and research. But as of today there are no facilities on ground to give room for the implementation. For example, there is no single electronic board in the whole of this university; even the microphones have been vandalized. No regular power supply and no ICT facilities on ground. 
Interviewee (3): The academic staffs have the willingness to use ICT, but the facilities are not on ground. There are some staff that use ICT for partial usage but it is not comprehensive. This guideline should be tailored towards removing ICT phobia.

Interviewee (4): The academic staff have the intention of using ICT, but the facilities are not available, no power supply and poor internet connectivity. Some of the academic staff that have Laptops do not know how to use it. They need training on how to use ICT for teaching and learning.

8.2 When asked about the curriculum on the issue of acceptance and use of ICT.

Interviewee (1): Definitely there will be a little review on the curriculum. The content will be the same but there will be a difference in the method of presentation. For example, whichever way you teach Mathematics one plus one will always be two whether digitally or in the old fashion way.

Interviewee (2): Our curriculum and methods of teaching is not prepared for ICT teaching now. In other words our curriculum is not tailored towards the usage of ICT. It's purely the traditional method of teaching where you will teach and even spoon feed the students with all the lecture notes. Therefore our curriculum needs a complete overhaul if we must use ICT for teaching and learning.

Interviewee (3): The curriculum has to be reviewed to allow ICT usage. I will say that the curriculum now is in analog, it has been design to be taught using manual methods. Thus our curriculum should be reframed to fit into the use of ICT.

Interviewee (4): Our old curriculum was drafted without focus on ICT but now the reviewed curriculum should be tailored towards the use of ICT.

The result also shows that effort expectancy which is related to how ease an individual believes the system is to use (Venkatesh et al., 2003), which is also referred to as perceived ease of use (PEOU), has correlation, $\mathrm{R}=.497$, and variance, $\mathrm{R}^{2}=.247$, significant with $\mathrm{p}$-value (.001).

8.3 When asked within your academic program so far how thorough is the acceptance and use of ICT and what would you recommend to the university.

Interviewee (1): To some extent there is an acceptance of ICT. There is a willingness to use but at the moment there is no ICT in use. We are trying to progressively encourage the use of ICT in our department. At the moment the use of ICT is minimal. The university should start to put in place the structures that will allow the use of ICT. For example, there is no electricity supply, thus we cannot use ICT. The classrooms are built along the old school of thought, some kind of modification is necessary for the classroom to be suitable for ICT lecture delivery. The university should make internet access to be widely available and of course academic staff should have access both in their offices and in the class. When the university addresses these major handicaps, then the use of ICT by the academic staff will be widespread.

Interviewee (2): Few years ago the university made the first move by given some academic staff soft loan to purchase Laptops. However this was not back up with good internet facilities or even intranet facilities. Laptops alone cannot be use for ICT teaching because the facilities to make for effective ICT usage are not available. There should be regular power supply and good internet services. The university should subscribe to sites that are not free so that academic staff can get current journal for academic work and research.

Interviewee (3): For now the acceptance of ICT is not encouraging among the academic staff, because most of the academic staff are still grabbling with the basis of learning how to use the keyboard properly. Therefore we have not reach the level that we can use it to teach our students. I will suggest to the university that the academic staff should embark on in-house training on how to use ICT for teaching and learning. The university should make ICT facilities available and to improve the internet services. The university should make sure that we have regular power supply by having a stand by generators for the schools.

Interviewee (4): The entire academic community will appreciate the adoption of ICT and its usage for our academic work, because we are in the global era. The academic staff are willing to accept and use ICT for their teaching and learning, however there are some challenges. The university should make ICT facilities and internet available for the academic staff. They should provide regular power supply by having stand by generators.

Performance expectancy (PE) that is perceived usefulness is significant with p-value (.023) and effort expectancy (EE) that is perceived ease of use is also significant with $\mathrm{p}$-value (.001). They are the factors associated with ICT acceptance and usage. Therefore this has answered objective 1 , which is to examine the factors associated with ICT acceptance and usage in MAUTECH. Therefore this has answered objective 1, which is to examine the factors associated with ICT acceptance and usage in MAUTECH. The study also confirms that the most influential UTAUT construct in MAUTECH, is effort expectancy (EE), with correlation, $\mathrm{R}=.497$ and variance, $\mathrm{R}^{2}=.247$, significant with $\mathrm{p}$-value (.001). (Answered objective 2).

The study shows that the most influential constructs outside UTAUT model is self efficacy (SE) in 
MAUTECH , with correlation, $\mathrm{R}=.445$ and variance, $\mathrm{R}^{2}$ $=.198$, significant with $\mathrm{p}$-value (.001).

8.4 When asked about the most important thing that would enable them to accept and use ICT.

Interviewee (1): The important things that will assist academic staff to accept and use ICT are:

Ownership of Laptops and PCs; Cheap access to internet; constant power supply with dedicated generators as stand by. We have only one projector, which means that only one person can use it at a time. Human beings are resistance to change, so academic staff needs some encouragement to use ICT for their teaching and learning. They also need Lab and lecture halls equip with ICT facilities. They need training and re-training on the use of ICT (gradually transferring their lecture notes on slides) for teaching and learning.

Interviewee (2): Justice and equity must return to our system for academicians to accept and use ICT for their teaching and research. A lot of lecturers are just on the job to keep body and soul together, but their minds are no longer on the job. Some have never reviewed their notes for the past ten years, how is it possible to incorporate ICT into teaching and research by such lecturers? ICT usage encourages one to one interaction in sizeable classes, but here the classes are too large, with minimum of 300 students per class in the lower levels. The university must look into these. Sponsorship to conference, workshops etc should be based on merit and not on favoritism as it exist now. There should be training and re-training for academic staff, this will encourage them to convert their traditional notes to electronic form. ICT Facilities must be available, with regular power supply.

Interviewee (3): To encourage the academic staff to accept and use ICT, there must be training session for both new and old academic staff. Now that the university is insisting that exam results should be processed using ICT, lecturers should be mandated to learn how to use ICT for their teaching and learning. The university should make the issue of power their priority. Once there is no light the issue of ICT is a closed issue. The university should upgrade its internet service and allow access for the academic staff at a low rate of charge if not free. Incentives should be given to the academic staff in form of soft loan to purchase their own Laptops and other software as the case may be.

Interviewee (4): The University should prepare an enabling environment to bring about the needed change. Electricity supply should be stable; internet should be accessible by the academic staff; ICT Facilities should be available; academic staff should be given incentives in form of soft loan to procure their own Laptops and software. There should be training and re-training for the

59 | P a g e academic staff on how to use ICT for teaching and learning.

The study also certifies that some of the academicians in MAUTECH are still having the fear of using ICT for teaching and learning.

8.5 When asked whether they support the idea of developing a guideline for ICT acceptance and usage for university academic staff.

Interviewee (1): I believe that it's possible to develop an ICT guideline for academic staff. Much has been said on ICT verbally on usage from primary education to the university. Proper steps are not taken because there is no guideline to follow. A guideline which will serve as a blue print, is necessary for the academic staff to move on target. The essence of the guideline is to show that ICT acceptance and usage should be achieved at a particular period and that is what we need. As long as we keep talking about it, if there is no guideline we will never get there. A guideline is a necessity on the use of ICT for teaching and research. We must also carry along the entire stakeholder for the guideline to be workable. Nothing never get done when you did not enforce it, the activities on the guideline must have a time frame.

Interviewee (2): Developing Guideline for ICT usage for teaching and learning will be a great invention. It is true that people find it difficult to adopt to change but when there is a guideline ICT phobia will be reduced to minimal with time. Lecturing in Nigeria has become a part-time job, so any guideline that will encourage lecturers to get acquitted with ICT in training and usage for teaching and research is a welcome idea. The guideline should be tailored towards removing ICT phobia. It should be tailored towards motivating the lecturers to use ICT for their lectures. The guideline should be tailored towards indigenization of ICT for teaching in Nigerian context. The guideline should be developed for a particular university so that if it is workable other public university will buy the idea. In other words, the guideline should be developing to start from somewhere.

Interviewee (3): A guideline is needed for ICT usage but this may not be useful to older lecturers that are about to retire. The guideline should be a form of transformational step to step training for the academic staff. The guideline should specify the responsibilities of the management and that of the academic staff. It should be mandatory for all academic staff to participate in the training depending on your status.

Interviewee (4): Guideline for ICT usage is a welcome idea; this will serve as a path way of transformation. The guideline should serve as a blue print of transforming academic staff into ICT literate and users in their workplace.

$$
\text { www.ijctonline.com }
$$




\section{Conclusion}

Using the mixed method approach, the quantitative phase shows that, the perceived usefulness (PE) is significant with p-value (.023) and the perceived ease of use (EE) is significant with p-value (.001). The results shows that the intention to accept and use ICT by the academic staff is a function of various concepts including the understanding that ICT is useful and it is not difficult to use. However the qualitative phase shows that it is true that the academicians intent to use ICT but the conditions and environment are not encouraging, classrooms are poorly designed. No regular power supply, no ICT facilities on ground and poor internet connectivity. It also expressed the fact that although some academic staff have Laptops, they need training on how to use it for teaching and learning. The qualitative approach interprets the statistical significant of PE and EE as: 'there is a willingness to use ICT by the academic staff. However at the moment there is no ICT in use per say because of the environmental challenges, thus the use of ICT is minimal.

The study confirms that performance expectancy (PE), significant with p-value (.023) and effort expectancy (EE), significant with p-value (.001) are found to be the most significant predictors of academic staff acceptance and use of ICT. This has answered objective 1 , which is to examine the factors associated with ICT acceptance and usage in MAUTECH. The study also confirms that the most influential UTAUT constructs in MAUTECH is effort expectancy (EE), with correlation, $\mathrm{R}=.497$ and variance, $\mathrm{R}^{2}=.247$, significant with p-value (.001) which answers objective 2 .

Again the statistical result from the study shows that the most influential constructs outside UTAUT model is self efficacy (SE) in MAUTECH, significant with p-value (.001). Computer self efficacy refers to 'what individual believes they can do with computer (ICT) skills they possess. The qualitative phase shows that a lot of lecturers are just on the job to keep body and soul together, but their minds are no longer on the job. Therefore they need training and re-training on the use of ICT for teaching and learning. Academic staffs need incentives in form of soft loan to procure their own Laptops and software.

The quantitative phase of the study certifies that some of the academicians in MAUTECH are still having the fear of using ICT for teaching and learning. They need to learn the basics of the technologies that will be most useful in their teaching and learning. The qualitative phase shows that, ICT guideline which will serve as a blue print is necessary. It is true that people find it difficult to adapt to change but when there is a guideline ICT phobia will be reduced to minimal with time.

The mixed method approach has given the true picture of the acceptance and usage of ICT in Nigerian public

60 I P a g e university. The quantitative phase shows the constructs that have significant influence on acceptance and use of ICT, while the qualitative phase interprets the in-depth meaning of the statistical results and the environmental challenges that most be tackled to realize the full vision.

\section{Acknowledgment}

The authors would like to thank Prof. V. Venkatesh for allowing the use of UTAUT for this research. In addition, the authors gratefully acknowledge UTM, Research Universiti Malaysia for their support and encouragement.

\section{Reference}

Aduke, A. F. (2008). Usage and Challengesof Information and Technology(ICT) in Teaching and Learningin Nigerian Universities. Asian Journalof Information Technology, 7(7), 290295.

AI- Qeisi, K. (2009). Analyzing the use of UTAUT model in explaining an online behaviour: Internet banking adoption. Unpublished $\mathrm{PhD}$ thesis, Brunel University. [Electronic Version]. Retrieved 5 August 2009.,

Aina, L. O. (2002b). General issues in Research, in Research in Information Sciences: an African Perspective, edited by LO Aina. In. Ibadan: Stirling-Horden Publishers (Nig.) LTD, p.185200.

Altrichter, H., Feldman, A., Posch, P., \& Somekh, B. (Eds.). (2008). Teachers investigate their work; An introduction to action research across the professions.

Archibong, I. A., \& Effiom, D. O. (2009). ICT in University Education: Usage and Challenges among Academic Staff. . Africa Research Review, 3(2), 404-414.

Barati, S., \& Mohammadi, S. (2009). An efficient model to improve customer acceptance of mobile banking. ( Accessed 18 June 2010) [Electronic Version],

Birth, A., \& Irvine, V. (2009). Preservice teachers' acceptance of ICT integration in the classroom: applying the UTAUT model. Educational media international,, 46(4), 295-315.

Bryman, A. (2004). Social Research Methods. Oxford: Oxford University Press.

Chen, L. (2005). Changing language teaching thruogh language testing: . In a washback study (pp. 72). Cambridge: Cambridge University Press.

Clarke, R. (1999). A primer of diffusion of innovation theory. (Accessed 19 September 2006). [Electronic Version],

Creswell, J. W., \& Plano Clark, V. L. (2007). Designing and Conducting Mixed Methods Research. Thousand Oaks, CA: Sage Publications. 
Denzin, N. (Ed.). (2006). Sociological Methods: A source book

Aldine transaction. ISBN9780-202308401 (5th edition).

Dixon-Woods, M., Agarwal, S., Young, B., Jones, D., \& Sutton, A. (2004). Integrative approaches to qualitative and quantitative evidence. (Accessed 17 April 2008). [Electronic Version],

Dunning, H., Williams, A., Abonyi, S., \& Crooks, V. (2008). A Mixed Method Approach to Quality of Life Research: A Case Study Approach. Social Indicators Research,, 85(1), 145-158.

Ekundayo, M. S. E., J. M. (2009). Capacity contraints in developing countries: A need for more e-learning space? The case of Nigeria. Paper presented at the Proceeding ascilite Auckland.

Fishbein, M., \& Ajzen, I. (1975). Belief, Attitude, Intention, and Behavior:. In An Introduction to Theory and Research Reading. MA: AddisonWesley.

Gall, Gall, \& Borg. (2005). Applying Educational Research. Boston: Pearson Education, Inc.

Garson, G. D. (2006). Multiple Regression Statistics. Helping by statistics solution. online.

Gengatharen, D., \& Standing, C. (2004). Regional emarketplaces: towards a unified theoretical framework for assessing facilitators and inhibitors of success. (Accessed 5 April 2007). [Electronic Version],

Gesci. (2007). Global e-schools and communities initiatives: Infrastructure and connectivity. (Publication.:

Ghobakhloo, M., Zulkifli, N., \& Aziz, F. (2010). The interactive model of user information technology acceptance and satisfaction in small and medium-size enterprises. European Journal of economics, finance and administrative sciences, 9. (Accessed 18 June 2010).

Gubahar, Y. (2008). ICT Usage in Higher Education: A Case study on Preservice Teacher and Instructors. The Turkish Online Journal of Educational Technology, 7(1).

Ijeoma, A. A., Joseph, E. O., \& Franca, A. (2010). ICT Competence among Academic staff in Unversities in Cross Rivers State, Nigeria. . Computer and Information Science, 3(4), 109 115.

Jayasingh, S., \& Eze, U. (2010). The roleof moderating factors in mobile coupon adoption: an extended TAM perspective. Communications of the IBIMA, 2010. (Accessed 21 June 2010). [Electronic Version],

Johnson, \& Onwuegbuzie. (2004). Mixed methods research: A research paradigm whose time has come. Education Researcher, 33(7), 14-26.

Johnson, R., Onwuegbuzie, A., \& Turner, L. (2007). Towards a Definition of Mixed Method

61 | P a g e
Research. Journal of Mixed Methods Research, 1(2), 112-113.

Kothari, C. (2004). Research methodology: methods and techniques. 2nd edition, New Delhi: New Age International (P) LTD Publishers. In.

Kripanont, N. (2007). Using technology acceptance model of internet usage by academics within Thai Business Schools. Unpublished PhD Thesis, Victoria University. (Accessed 6 Jan 2008).

Legris, Ingham, \& Collerette. (2003). Why do people use information technology? A Critical Review of the technology Acceptance Model. Information and Management, 40, 191-204.

Louho, R., Kallioja, M., \& Oittinen, P. (2006). Factors affecting the use of Hybrid media applications. Graphic arts in Finland,, 35(3), 11-21.

Maxwell, J., \& Loomis, D. (Eds.). (2003). Mixed Method desgn: An alternative approach. In: A. Tashakkori and C. Teddlie[Eds]: : Thousand Oaks CA : Sage Publication.

Minishi-Majanja, M., \& Kiplang'ati, J. (2005). The diffusion of innovation theory as a theoretical framework in library and information science research. South African journal of library \& information science, , 71(3), 211-224.

Morgan, D. (1998). Practical strategies for combining Qualitative and Quantitative Methods: Application to Health Research. Qualitative Health Research,, 8(3), 362-376.

Ogunsola, L. A., \& Aboyade, W. A. (2005). Information and Communication Technologyin Nigeria: Revolution or Evolution. Journal of Social Sciences, 11(1), 7-14.

Oyelekan, B. A., C. N. (2004). Dynamics of adoption and usage of ICTs in African universities: a study of Kenya and Nigeria. Technovation, 24, 841-851.

Perez, M. P., Sanchez, A. M., Carnicer, P. L., \& Jimenez, M. J. V. (2004). A technology acceptance model of innovation adoption: the case of teleworking. European Journal of innovation management, 7(4), 280-291.

Rao, V. (Ed.). (1998). "Wife-Abuse, Its Causes and Its Impact on Intra-Household Resource Allocation in Rural Karnataka: A Participatory Econometric Analysis. In Maithreyi Krishnaraj, RatnaSudarshan, and Abusaleh Sharif, eds. Gender, Population, and Development. Oxford, U. K. : Oxford University Press.

Rao, V., \& Ibanez, M. A. (2003). " The Social Impact of Social Funds in Jamaica: A Mixed-Methods Analysis of Participation, Targeting and Collective Action in Community-Driven Develpment". Policy Research Working Paper 2970. World Bank, Development Research Group, Washington, D. C. Processed.

w w w. ijctonline.com 
Schaper, L. K., \& P., P. G. (2007). An investigation of factors affecting technology acceptance and use decisions by Australian allied health therapists, in Proceedings of the 40th Paper presented at the Hawaii International Conference on System Sciences. (Accessed 2 April 2007).

Stacy, W., \& Sally, J. (1999). Technology diffusion within educational institutions: applying the technology acceptance model. (Accessed 29 March 2007) [Electronic Version],

Surry, \& Ensminger. (2006). Facilitating the use of web based learning by higher education faculty [Electronic Version], 16. Retrieved March 18, 2007 from ERIC Database,

Szajna, B. (1996). Empirical evaluation of the revised technology acceptance model. Management Science, 42(1), 85-92.

Tashakkori, A., \& Teddlie, C. (Eds.). (2003). Handbook of Mixed Methods in Social and Behavioral Research: London

Sage:Publication.

Van Biljon, J., \& Renaud, K. (2009). Distance education as enabler in crossing the digital divide: will phoenix fly? in proceedings of the 3rd International IDIA Development informatics Conference. Paper presented at the IDIA Development Informatics Conference. ( Accessed 21 Jue 2010). Berg-en-Dal, South Africa.

Venkatesh, \& Davis. (2000). A theoretical extension of technology acceptance model: Four longitudinal field studies. Management Science, 46(2), 186204.

Venkatesh, Davis, Morris, \& Davis, G. B. (2003). User acceptance of information technology: Towards a unified view. MIS Quarterly, 27(3), 425-478.

Zhang, P., Li, N., \& Sun, H. (2006). Affective Quality and Cognitive Absorption: Extending Technology Acceptance Research. Paper presented at the The Hawaii International Conference on System Sciences.

\section{Authors - Bibliography}

[1]N.D.Oye, receive his M.Tech OR (Operations Research) degree from the Federal University of Technology Yola- Nigeria in 2002. He is a lecturer in the department of Mathematics and Computer Science in the same University (for the past 15yrs). At the moment he is a Phd student in the department of Information Systems in the Faculty of computer Science and Infor-mation systems at the Univeristi Teknologi Malaysia, Skudai, Johor, Malaysia.+60129949511 oyenath@ yahoo.co.uk

\section{[2] Noorminshah A. Iahad, PhD}

She did her PhD at the School of Informatics, The University of Manchester. She worked with Professor Linda Macaulay from the Interactive Systems Design research section in the same school and Dr George Dafoulas from the School of Computing Science, Middlesex University. Her research is on investigating interaction patterns in asynchronous computer-mediatedcommunication. Her work includes analysing threaded discussion transcripts from the discussion feature of a well known Leaning Management System: WebCT. FSKSM, UTM 81310 Skudai, Johor, Malaysia.Email : minshah@utm.my , noorminshah@gmail.com,

Office : +6075532428

[3] NorZairah Ab. Rahim PhD,

Faculty of Computer Science and Information systems, Universiti Teknologi Malaysia, 81310 Skudai Johor. +60175532407, nzairah@utm.my I am a lecturer in Department of Information Systems, Faculty of Computer Science \& Information Systems. Universiti Teknologi Malaysia (UTM Skudai) Academic Background : PhD (Computer Science), Universiti Teknologi Malaysia (2009) Master in Information Systems, University of Melbourne (2005) BSc. (Hons) in Information Studies (Information Systems Management), Universiti Teknologi Mara (2002) Research Interests : Technology appropriation, Organizational and individual technology adoption and use. 
Figure 1: Proposed model of perceived influence of academic performance for using SNS among FSKSM students

FSKSM (Faculty of Computer Science and Information Systems). 